\title{
Biosynthesis and Radical Scavenging Activity of Betalains during the Cultivation of Red Beet (Beta vulgaris) Hairy Root Cultures
}

\author{
Atanas Pavlov, ${ }^{\mathrm{a}, *}$, Petia Kovatcheva ${ }^{\mathrm{a}}$, Vasil Georgiev ${ }^{\mathrm{b}}$, Irina Koleva ${ }^{\mathrm{c}}$ \\ and Mladenka Ilieva ${ }^{\mathrm{a}}$ \\ ${ }^{a}$ Group of Applied Microbiology and Biotechnology, Institute of Microbilogy, \\ Bulgarian Academy of Sciences, 26 Maritza Blvd, 4002 Plovdiv, Bulgaria. \\ E-mail: lbpmbas@plov.omega.bg \\ b Department of Biotechnology, Higher Institute of Food and Flavour Industries, \\ 26 Maritza Blvd, 4002 Plovdiv, Bulgaria \\ c Department of Analytical Chemistry, Higher Institute of Food and Flavour Industries, \\ 26 Maritza Blvd, 4002 Plovdiv, Bulgaria \\ * Author for correspondence and reprint requests \\ Z. Naturforsch. 57 c, 640-644 (2002); received January 31/March 8, 2002 \\ Beta vulgaris, Betalains, Radical Scavenging Activity \\ Betalains biosynthesis and antiradical scavenging activity were investigated during cultiva- \\ tion of four hairy root cultures of Beta vulgaris, obtained from different cultivars (Bordo, \\ Egyptian, Detroit 2 and Detroit Dark Red). The best producer of betalains was a hairy \\ root culture from Beta vulgaris cv. Detroit Dark Red $(13.27 \mathrm{mg} / \mathrm{g}$ dry weight total pigment \\ production). The ethanol extract, derived from roots of the same culture grown for 15 days \\ under submerged conditions, showed a high antiradical activity ( $83 \%$ of inhibition of the \\ stable $\mathrm{DPPH} \bullet$ ).
}

\section{Introduction}

Red beet (Beta vulgaris) is a potential source of valuable water-soluble nitrogenous pigments, called betalains, which are composed of two main groups, the red betacyanins and the yellow betaxanthins. They are free radical scavengers and prevent active oxygen-induced and free radical-mediated oxidation of biological molecules (Pedreňo and Escribano, 2001). Accordingly, this pigment mixture has been used as a natural additive for food, drugs and cosmetic products in the form of beet juice concentrate or beet powder (Dörnenburg and Knorr, 1996).

Recently some investigations on hairy root cultures obtained from red beet were reported (Hamill et al., 1986; Taya et al., 1992; Taya et al., 1994; Mukundan et al., 1998). It is known that hairy root cultures are an alternative for the production of secondary plant products (Taya et al., 1992; Mano, 1989). They are usually considered as genetically stable, in contrast to callus cultures, because hairy roots originate from a single plant cell infection by Agrobacterium rhizogenes (Bourgaud et al., 1999). Furthermore, in contrast to dedifferentiated cells they grow in hormone-free medium and produce valuable secondary metabolites at a comparable rate to the original plants (Bourgaud et al., 1997).

\section{Materials and Methods}

\section{Plant material}

Seeds of red beet were purchased from local markets in Plovdiv, Bulgaria (cv. Detroit 2, Egyptian and Bordo) and in Burlington, Vermont, USA (cv. Detroit Dark Red). After seeding and outdoor growth for about four weeks leaves were subjected to hairy root induction. They were surface-sterilized for $10 \mathrm{~s}$ with $70 \%$ ethanol and then for 15 min. with sodium hypochlorite ( $2 \%$ available chlorine), thoroughly rinsed with sterile distilled water and dried on sterile tissue paper.

\section{Bacteria}

Agrobacterium rhizogenes ATCC 15834 was used. The bacteria were grown on YEB [Nutrient broth (Sigma) $8 \mathrm{~g} / \mathrm{l}$, yeast extract (Merck) $1 \mathrm{~g} / \mathrm{l}$, sucrose $5 \mathrm{~g} / \mathrm{l}$, agar (Merck) $15 \mathrm{~g} / \mathrm{l}$ and $\mathrm{MgSO}_{4}$ $0.5 \mathrm{~g} / 1 \mathrm{l}$ medium and were subcultured at 1-month intervals. Before transformation the bacteria were cultivated in liquid YEB in flasks $(100 \mathrm{ml})$ with $25 \mathrm{ml}$ medium on a shaker $(13 \mathrm{rad} / \mathrm{s})$ at $25^{\circ} \mathrm{C}$ for 
$16 \mathrm{~h}$. The obtained bacterial suspension was transferred to a sterile centrifuge tube and was centrifuged at $5000 \times g$ for $30 \mathrm{~min}$. The biomass of Agrobacterium was suspended in $20 \mathrm{ml}$ MurashigeSkoog (MS) hormone-free nutrient medium (Dixon, 1985) supplemented with $30 \mathrm{~g} / 1$ sucrose (the density of bacterial suspensions were between $0.4-0.6$ at $600 \mathrm{~nm}$ ). The obtained bacterial suspension was used for the establishment of the hairy roots.

\section{Establishment of "hairy root" culture}

The sterilized leaves were co-cultivated with the bacterial suspension (described above) in a flask $(100 \mathrm{ml})$ on a shaker $(11 \mathrm{rad} / \mathrm{s})$, at $26^{\circ} \mathrm{C}$, on dark for $3 \mathrm{~h}$. After that leaves were gently dried on sterile tissue paper and were transferred to a MS medium, supplemented with $30 \mathrm{~g} / \mathrm{l}$ sucrose and $5.5 \mathrm{~g} / \mathrm{l}$ "Plant" agar (Duchefa Biochemie BV, Haarlem, The Netherlands). Plantlets were cultivated at $26{ }^{\circ} \mathrm{C}$ under continuous light $(16 / 8$, light/ dark). After $76 \mathrm{~h}$ the infected leaves were transferred to hormone-free MS nutrient medium, supplemented with $30 \mathrm{~g} / 1$ sucrose, $5.5 \mathrm{~g} / \mathrm{l}$ "Plant" agar and $0.25 \mathrm{~g} / 1$ claforan (Hoechst Ltd., Instambul, Turkey) and cultivated under the same conditions. The appearance of hairy roots was observed four weeks later. The root segments $(20 \mathrm{~mm}$ long) were cut off, transferred to the same medium and cultivated at $26^{\circ} \mathrm{C}$ in the dark and subcultured at 21-days intervals (the first three subcultivations were carried out with the addition of $0.25 \mathrm{~g} / 1$ claforan).

\section{Cultivation of hairy root; preparation of extracts}

The B. vulgaris hairy roots used in the experiments were cultivated in a hormone-free liquid MS nutrient medium, supplemented with $30 \mathrm{~g} / \mathrm{l}$ sucrose. The cultivation was carried out in Erlenmeyer flasks $(200 \mathrm{ml})$ with $1 / 5$ net volume on a shaker $(11.6 \mathrm{rad} / \mathrm{s})$ at $26^{\circ} \mathrm{C}$ in the dark. For inoculation $0.5-1 \mathrm{~g}$ (for each flask) fresh hairy roots, grown on solid MS medium for 7 days, were used. The obtained hairy root cultures were subcultured for more than one year.

Fresh hairy roots were homogenized in 50\% ethanol ( $1 \mathrm{~g}$ fresh weight $/ 10 \mathrm{ml}$, three times). The homogenate was centrifuged at $10,000 \times g$ for $10 \mathrm{~min}$. The supernatant was used for the determination of betalains and radical scavenging activity.

\section{Analyses}

Cell growth. The hairy root growth was monitored by accumulated dry biomass (ADB), according to the equation: $A D B=F D W-I D W$ (ADB accumulated dry biomass; FDW - final dry weight of hairy root culture; IDW - initial dry weight of hairy roots, used for inoculation).

Dry biomass was measured according to Dixon (1985).

Betalains content. The content of betacyanins and betaxanthins in the extracts were determined spectrophotometrically (SHIMADZU UV-VIS 1240) following the method of Nilsson (1970).

Radical scavenging activity. The radical scavenging activity of ethanol extracts was determined after the method of von Gadow et al. (1997) and modified as follows. The extracts were studied at the ratio $0.04 \mathrm{mg}$ extract/ $1 \mathrm{~mol} \mathrm{DPPH} \bullet$. The sample contained: extract, $2.0 \mathrm{ml} \mathrm{DPPH} \bullet$ and ethanol until a total volume of $2.5 \mathrm{ml}$ was reached (the needed amounts of extracts were calculated on the basis of their dry weight). The prepared sample was incubated for $15 \mathrm{~min}$ in the dark at room temperature and the absorbance decrease at $517 \mathrm{~nm}$ was measured against a control sample (CS) containing the same amount of the extract used in the assay sample and ethanol (total volume of CS -2.5). A blank sample (BS) (without addition of antioxidant) containing $2 \mathrm{ml} \mathrm{DPPH} \bullet$ and $0.5 \mathrm{ml}$ EtOH was prepared and measured before every measurement of the sample of the relevant extract. DPPH• $\left(10^{-4} \mathrm{M}\right)$ standard solution was freshly prepared and kept in a flask protected against light with aluminium foil and stored at $4{ }^{\circ} \mathrm{C}$ between the measurements. All determinations were performed in three replicates. The radicalscavenging activity expressed as \% inhibition against DPPHo, was calculated according to Yen and Duh (1994):

$\%$ Inhibition $=\left[\left(\mathrm{A}_{\mathrm{B}}-\mathrm{A}_{\mathrm{A}}\right) / \mathrm{A}_{\mathrm{B}}\right] \times 100$

$\left(A_{A}\right.$ is the absorbance of the tested sample after $15 \mathrm{~min} ; A_{B}$ is the absorbance of the blank sample)

The data presented are the average from two independent experiments repeated twice. 


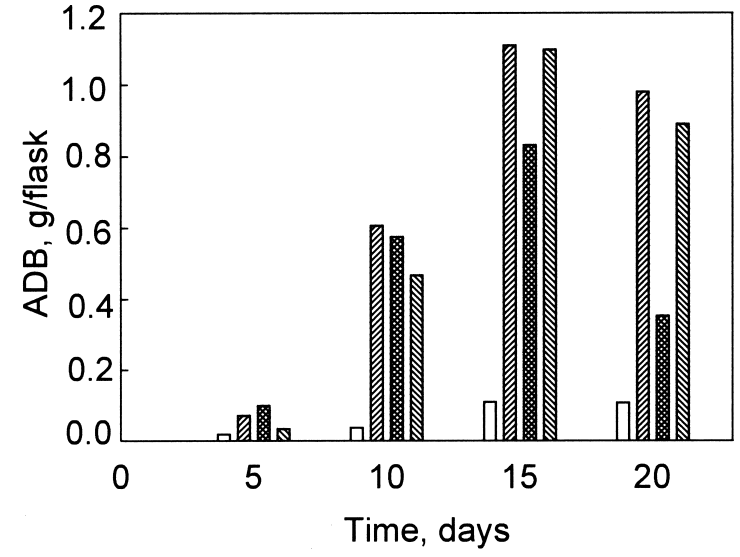

Fig. 1. Time course of growth of B. vulgaris hairy root cultures. $\square$ Beta vulgaris cv Bordo; שes Beta vulgaris cv Detroit 2; 经罯 Beta vulgaris cv Egyptian; vulgaris cv Detroit Dark Red. $A D B=F D W-I D W$ (ADB - accumulated dry biomass; FDW - final dry weight of hairy root culture; IDW - initial dry weight of hairy roots; used for inoculation).

\section{Results and Discussion}

Time course of B. vulgaris hairy root cultures growth

The fourth hairy root cultures obtained from different cultivars (Bordo, Detroit 2, Egyptian and Detroit Dark Red) of B. vulgaris were investigated. They were maintained for more than one year on the agar medium and were subcultured every 21 days. As a result of this subcultivation all of them showed stable growth and morphological characteristics. They were all profusely branched, with many lateral branches. The growing tips were colourless and in active-growing roots the pigmentation was mainly in orange (this zone is from $0.5 \mathrm{~cm}$ to $1.0 \mathrm{~cm}$ long). The remainder parts of roots were red. The same growth picture was observed by other researchers as well (Hamill et al., 1986).

The adaptation to submerged cultivation was comparatively easy. The hairy root cultures grew intensively and the maximum accumulated biomasses were read on the $15^{\text {th }}$ day of cultivation (1.11 g ADB/flask, $1.10 \mathrm{~g} \mathrm{ADB/flask} \mathrm{and} 0.83 \mathrm{~g}$ ADB/flask for B. vulgaris L. cv Detroit 2, Detroit Dark Red and Egyptian, respectively) (Fig. 1). At the end of the cultivation the hairy root cultures had increased their mass over 20 times. B. vulgaris cv Bordo hairy root culture is an exception, with a slow growth, and on $15^{\text {th }}$ day of the cultivation the amount of ADB is about $0.11 \mathrm{~g} /$ flask.

Time course of betalains biosynthesis by B. vulgaris hairy root cultures

The content of betalains during the cultivation of different hairy root cultures of $B$. vugaris are shown on Figure 2. The time course of betalain biosynthesis follows that of growth. A maximal amount of pigments in all four cultures are biosynthesized and accumulated in the roots on day $15^{\text {th }}$ of the cultivation. The total amount of pigments, biosynthesized by B. vulgaris cv. Detroit

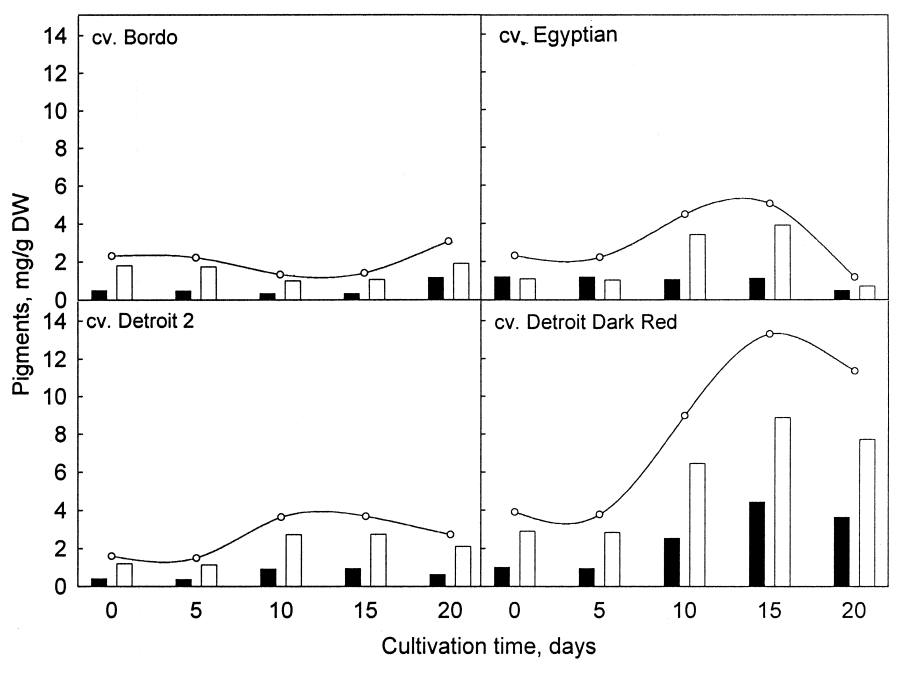

Fig. 2. Time course of pigment biosynthesis by $B$. vulgaris hairy root cultures. betacyanins; $\square$ betaxanthins; $-\mathrm{O}-$ total pigment production. 


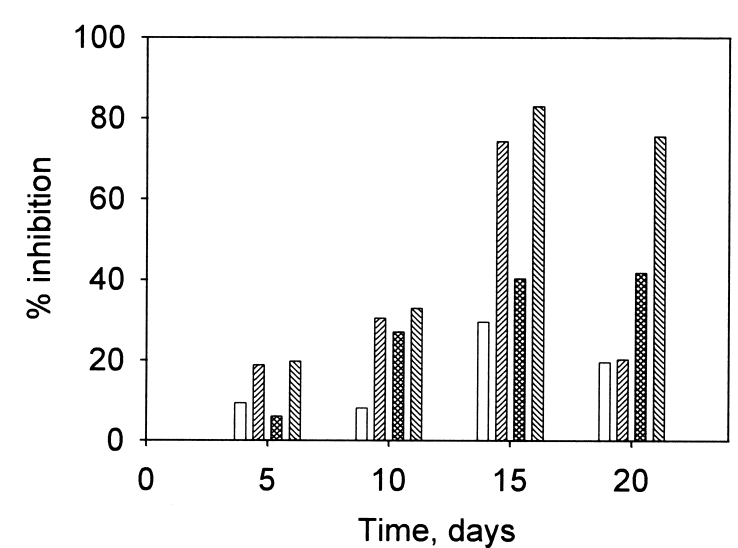

Fig. 3. Changes in radical scavenging activity in ethanol extracts during cultivation of $B$. vulgaris hairy root cultures. $\square$ Beta vulgaris cv Bordo; שes Beta vulgaris cv Egyptian; Beta vulgaris cv Detroit 2; garis cv Detroit Dark Red.

Dark Red (13.2 mg/g DW), is several times higher than the pigments biosynthesized by the other hairy root cultures $(3.1 \mathrm{mg} / \mathrm{g}$ DW for $B$. vulgaris cv. Bordo, $5.0 \mathrm{mg} / \mathrm{g}$ DW for B. vulgaris cv Egyption and $3.7 \mathrm{mg} / \mathrm{g}$ DW for B. vulgaris cv Detroit 2, respectively). The maximal amount $(13.2 \mathrm{mg} / \mathrm{g}$ DW) of pigments accumulated in the roots during cultivation of $B$. vulgaris cv Detroit Dark Red hairy root culture is considerably higher than the content in the roots used as inoculum. This finding is in contrast to Hamill et al. (1986). They reported that at the end of the cultivation of $B$. vulgaris hairy root cultures, the amount of betalains, in the roots are equal to the amount of these metabolites in the roots used as inoculum. In our opinion this difference is due to the fact that the quoted authors used as inoculum roots at a stationary stage of growth (Hamill et al., 1986) whereas in our experiments cultures at the beginning of the exponential phase (see "Materials and Methods") have been used as inoculum. All four hairy root cultures, obtained from different cultivars of $B$. vulgaris biosynthesize betaxanthins in larger amounts compared to betacyanins. No major changes in the ratio of betacyanins and betaxanthins were observed during cultivation.

\section{Radical scavenging activity}

In Figure 3 the changes in the efficiency of the ethanol root extracts to inhibit DPPH• formation are shown follow the time course of biosynthesis of the betalains in all four examined cultures. The extracts obtained from roots of $B$. vulgaris cv Datroit Dark Red hairy root culture showed the highest antiradical activity on the $15^{\text {th }}$ day of cultivation $(83 \%)$ which coincides with the maximal values of the biosynthesised betalains. This result indicates that the concentration of the betalains and the antiradical activity of the ethanol extracts are directly correlated.

The red beet hairy root culture, obtained from cv Detroit Dark Red is selected as a prospective producer of betalain pigments. It has stable morphological, growing and biosynthetic characteristics and biosynthesizes $13.2 \mathrm{mg} / \mathrm{g}$ DW pigments ( $4.4 \mathrm{mg} / \mathrm{g}$ DW are betacyanins and $8.8 \mathrm{mg} / \mathrm{g}$ DW betaxanthins, respectively). In comparison $B$. vulgaris hairy root cultures obtained by other authors produce comparable or considerably smaller amounts (Hamill et al., 1986; Taya et al., 1994; Mukundan et al., 1999). The antiradical activity of the ethanol extract obtained from 15-day roots of B. vugaris hairy root culture (cv. Detroit Dark Red) ( $83 \%$ inhibition of DPPH $\bullet$ ) is higher than that of the well-known synthetic antioxidant BHT (butylated hydroxytoluene) (Kovatcheva et al., 2001).

In conclusion, B. vulgaris hairy root culture (cv. Detroit Dark Red) can be considered as a good producer of betalain pigments. The high antiradical activity found in the ethanol extracts is a good base for development of a biosynthetic process to obtain additives with a potential for application in the food, cosmetic and pharmaceutical industry.

\section{Acknowledgement}

The authors gratefully acknowledge financial support for this work from the National Research Foundation of Bulgaria. 
Bourgaud F., Bouque V., Gontier E. and Guckert A (1997), Hairy root cultures for the production of secondary metabolites. AgBiotech News Inform. 9, $205 \mathrm{~N}-208 \mathrm{~N}$.

Bourgaud F., Bouque V. and Guckert A. (1999), Production of flavonoids by Psoralea hairy root cultures. Plant Cell Tiss. Organ Cult. 56, 97-104.

Dixon R. A. (1985), Isolation and maintenance of callus and cell suspension cultures. In: Plant Cell Culture a Practical Approach (R. A. Dixon, ed.). IRL Press, Oxford, pp. $1-20$.

Dörnenburg H. and Knorr D. (1996), Generation of colors and flavors in plant cell and tissue cultures. Crit. Rev. Plant Sci. 15, 141-168.

Hamill J. D., Parr, A. J., Robins R. J. and Rhodes M. J. C. (1986) Secondary product formation by cultures of Beta vulgaris and Nicotiana rustica transformed with Agrobacterium rhizogenes. Plant Cell Rep. 5, 111114.

Kovatcheva E. G., Koleva I. I., Ilieva M., Pavlov A., Mincheva M. and Konushlieva M. (2001), Antioxidant activity of extracts from Lavandula vera MM cell cultures. Food Chem. 72, 295-300.

Mano Y. (1989), Variation among hairy root clones and its application. Plant Tissue Cult. Lett. 6, 1-9.

Mukundan U., Bhide V., Singh G. and Curtis W. R. (1998), $\mathrm{pH}$ mediated release of betalains from transformed root cultures of Beta vulgaris. Applied Microbiol. Biotechnol. 50, 241-245.
Mukundan U., Bhide V. and Dawda H. (1999), Production of betalains by hairy root cultures of Beta vulgaris L. In: Plant Cell and Tissue Culture for the Production of Food Ingredients (T-J. Fu, G. Singh and W. R. Curtis, eds). Kluwer Academic/Plenum Publ., New York, pp. 121-128.

Nilsson T. (1970), Studies into the pigments in Beetroot (Beta vulgaris L. ssp. vulgaris var. rubra L.). Lantbrukshogskolans annaler. 36, 179-219.

Pedreňo M. A. and Escribano J. (2001), Correlation between antiradical activity and stability of betanine from Beta vulgaris $\mathrm{L}$ roots under different $\mathrm{pH}$, temperature and light conditions. J. Sci. Food Agric. 81, $627-631$.

Taya M., Mine K., Kino-Oka M., Tone S. and Ichi T. (1992), Production and release of pigments by culture of transformed hairy root of red beet. J. Ferment. Bioeng. 73, 31-36.

Taya M., Yakura K. Kino-Oka M. and Tone S. (1994), Influence of medium constituents on enhancement of pigment production by batch culture of red beet hairy roots. J. Ferment. Bioeng. 77, 215-217.

Von Gadow A., Joubert E. and Hansmann C. F. (1997), Comparison of the antioxidant activity of rooibos tea (Aspalanthus linearis) with green, oolong and black tea. Food Chem. 60, 73-77.

Yen G. C. and Duh P. D. (1994), Scavenging effect of methanolic extracts of peanut hulls on free-radical and active-oxygen species. J. Agricult. Food Chem. 425, 629-632. 